\title{
Biocompatibility of Carbon Nanoparticles in HeLa Cells is Dictated by Synthesis and Sterilization Procedures
}

\author{
Elisa Panzarini, Cristian Vergallo, Stefania Mariano, Luciana Dini* \\ Department of Biological and Environmental Science and Technology (Di.S.Te.B.A.), University of Salento, Lecce, Italy
}

\section{Email address:}

elisa.panzarini@unisalento.it (E. Panzarini), cristian.vergallo@unisalento.it (C. Vergallo), stefania.mariano@unisalento.it (S. Mariano), luciana.dini@unisalento.it (L. Dini)

\section{To cite this article:}

Elisa Panzarini, Cristian Vergallo, Stefania Mariano, Luciana Dini. Biocompatibility of Carbon Nanoparticles in HeLa Cells is Dictated by Synthesis and Sterilization Procedures. Nanoscience and Nanometrology. Vol. 2, No. 1, 2016, pp. 1-7.doi: 10.11648/j.nsnm.20160201.11

\begin{abstract}
Due to their unique chemical and physical properties, carbon-based NanoMaterials (C-NMs) are largely exploited in biomedicine, i.e., cell and tissue imaging, drug delivery and tissue engineering scaffold, even if reports regarding their toxicity are still conflicting. In fact, biological effects strictly depend on the dynamic physicochemical characteristics of CNMs, which in turn are strongly influenced by the procedures of their synthesis, and nanometrological techniques, e.g., Electron Microscopy (EM)-based analysis, are becoming the main tool for researchers to characterize nanoproducts. The aim of the present work is the study of the influence of synthesis and sterilization protocols on the size, shape, stability and biocompatibility of carbon NanoParticles (C-NPs). C-NPs were synthesized by using graphite as bulk material through an electrochemical method applying a constant voltage of $30 \mathrm{~V}$ and different times of synthesis. The C-NPs solution was sterilized by adopting different sterilization protocols during and/or after the synthesis. Size, shape and stability were studied by TEM and spectroscopy, while biocompatibility was tested in HeLa cells. Synthesis and sterilization procedures did not influence size, shape and stability of C-NPs, but interfered with C-NPs biocompatibility. In fact, irrespective of time of electrolysis process, the NPs show spherical shape with an average diameter of $7 \mathrm{~nm}$. UV-visible spectra show typical peak of carbonaceous materials that falls at $236 \mathrm{~nm}$ without aggregation and sedimentation. However, when NPs obtained at 90 min of synthesis were twice autoclaved the peak shifted to $257 \mathrm{~nm}$. HeLa cells were incubated with different C-NPs solutions administered at different concentrations, ranging from $8 \times 10^{5}$ to $1.6 \times 10^{7} \mathrm{C}-\mathrm{NPs} / \mathrm{cell}$, for different times (4, 24 and $48 \mathrm{~h}$ ). Cell viability was CNPs concentration- and time of culture-dependent; interestingly, also the time of electrolysis process used during particles synthesis and procedures adopted to sterilize C-NPs solutions largely influenced cells response.
\end{abstract}

Keywords: Carbon Nanoparticles, Biocompatibility, Synthesis Parameters, Sterilization Procedures

\section{Introduction}

Carbon-based NanoMaterials (C-NMs), such as single or multi-walled nanotubes, fullerenes, nanodiamonds, and graphenes, are becoming key materials for various industrial applications due to their unique combinations of chemical and physical properties (i.e., thermal and electrical conductivity, high mechanical strength, and optical properties) [1]. They have promising applications in nanoelectronics [2], microelectrical devices [3], electrochemistry [4,5], sensors [6], catalysis [7] and ultracapacitors [8-10]. In recent years, $\mathrm{C}$-NMs are receiving many attention also in biomedical research [11], mostly in bioimaging [12,13] and drug delivery $[14,15]$. Engineered carbon NanoParticles (C-NPs) can be synthesized by numerous methods such as the candle soot method [16], laser induced pyrolysis of hydrocarbons
[17], low temperature solution synthesis [18], electrochemical oxidation of graphite [19], microwave pyrolysis of sucrose [20], proton-beam irradiation of nanodiamonds [21], thermal decomposition of organic compounds [22,23], using mesoporous silica NPs as template [24], and using polyacrylonitrile as a NPs precursor [25].

Due to the widespread application of nanosized materials, a precise characterization is need for their safe and responsible exploitation. This has opened new nanometrology challenges for an accurate morphological characterization, near atomic resolution, to ascertain NPs elemental composition or to exclude the presence of contaminants introduced during the synthesis procedures. Thus, the precise knowledge of the NPs characteristics, 
monitored by nanometrological techniques, is pivotal to ensure their biocompatibility and define their biological effects [26].

Unfortunately, determining biocompatibility or toxicity of C-NPs is quite complicated. The surface coating, the presence of metal catalysts and/or graphite, the dispersion properties, and the tendency to deposit as aggregates, because of high Van der Waals's forces, influence greatly the behavior of these NPs. Epidemiological and experimental studies, for example, have confirmed the role of C-NPs in aggravating pulmonary disorders such as asthma as well as lung cancer, pulmonary fibrosis and systemic cardiovascular disorders [27]. C-NPs have also a negative impact on the correct development of sea urchin, thus opening environmental risk concerns [28-30]. At the same time, C-nanotubes are largely exploited in bioimaging and in drug delivery [31].

Taking into account the fact that no data are available in the literature about the effect of the synthesis methods of CNPs on the biocompatibility, in this study we evaluated the cytotoxicity of electrochemical synthesized C-NPs by using graphite as bulk material. In particular, we investigated the influence of synthesis time and sterilization procedures on biocompatibility of C-NPs solution obtained. C-NPs were characterized by TEM and spectroscopy and biocompatibility was evaluated by using HeLa cells in in vitro experiments.

\section{Materials and Methods}

\subsection{Chemicals}

All chemicals were of analytical grade and were purchased from Sigma-Aldrich (Sigma, St. Louis, MO, USA) unless otherwise indicated.

\subsection{Synthesis of C-NPs}

High purity graphite rod (99.99\%, SPI Supplies Division Structure Probe Inc., West Chester, PA, USA) was used as an anode (5 mm diameter), and a stainless steel rod AISI 1016, 5 mm diameter (Swagelok, Solon, OH, USA), was used as a cathode. The electrodes were immersed in a beaker containing Milli-Q water at a distance of $10 \mathrm{~mm}$. A constant voltage of $30 \mathrm{~V}$ was applied during the electrolysis process. Simultaneously, the colloidal solution was forcedly dispersed by an ultrasonicator $(1000 \mathrm{~W}$ power output; $100 \pm 5 \mathrm{kHz}$ frequency) (Flexonic-1200-35/72/ 100G, Mirae Ultrasonic Tech., Co., Ltd., Guro gu Seoul, South Korea) to prevent the aggregation of NPs. Different times of the synthesizing reaction and sterility conditions have been tested as reported in Table 1.

$20 \mathrm{~mL}$ of NPs solution was diluted with $30 \mathrm{~mL}$ of distilled water. The average size, size distribution, morphology of NPs were studied by high resolution TEM and UV-visible spectroscopy. The stability of different C-NPs concentrations over the time was assayed in complete Eagle's Minimum Essential Medium (EMEM).

Table 1. Scheme of the experiments.

\begin{tabular}{|c|c|c|c|c|}
\hline \multicolumn{2}{|c|}{$\begin{array}{l}\text { Parameters for electrochemical } \\
\text { synthesis of C-NPs }\end{array}$} & \multirow{2}{*}{$\begin{array}{l}\text { Sterile protocols (before and/or after } \\
\text { C-NPs administration to cells) }\end{array}$} & \multirow{2}{*}{$\begin{array}{l}\text { Investigations performed } \\
\text { on C-NPs }\end{array}$} & \multirow[b]{2}{*}{ on C-NPs treated cells } \\
\hline $\begin{array}{l}\text { Electric potential } \\
\text { difference } \Delta V(\text { volt })\end{array}$ & $\begin{array}{l}\text { Time } \\
\text { (min) }\end{array}$ & & & \\
\hline & & None & \multirow{6}{*}{$\begin{array}{l}\text { Spectroscopy (UV-visible } \\
\text { spectra from } 200 \text { to } 1000 \mathrm{~nm} \text { ) } \\
\text { and TEM characterization of } \\
\text { freshly synthesized and } 6 \text { days } \\
\text { old C-NPs }\end{array}$} & HeLa cells incubated with: \\
\hline 30 & 90 & C-NPs solution autoclaved twice at & & i) $8 \times 10^{5} \mathrm{C}-\mathrm{NPs} /$ cell \\
\hline & & $121^{\circ} \mathrm{C}, 2 \mathrm{~atm}$ for $20 \mathrm{~min}$ & & ii) $1.6 \times 10^{6} \mathrm{C}-\mathrm{NPs} /$ cell \\
\hline " & 150 & C-NPs synthesized under sterile & & iii) $3.2 \times 10^{6} \mathrm{C}-\mathrm{NPs} /$ cell \\
\hline & & conditions (materials and workplaces) & & iv) $8 \times 10^{6} \mathrm{C}-\mathrm{NPs} / \mathrm{cell}$ \\
\hline$"$ & 190 & $\begin{array}{l}\text { C-NPs solution microfiltered with } \\
\text { filters (pores sized } 0.2 \mu \mathrm{m} \text { ) }\end{array}$ & & $\begin{array}{l}\text { v) } 1.6 \times 10^{\prime} \mathrm{C}-\mathrm{NP} \text { /cell } \\
\text { at } 4,24 \text { and } 48 \text { h of incubation: MTT } \\
\text { LM (phase contrast) }\end{array}$ \\
\hline
\end{tabular}

\subsection{Physical Analyses of C-NPs}

UV-visible spectra were recorded in the range between 200 and $1000 \mathrm{~nm}$ by using a T80 spectrophotometer (PG Instruments Ltd., Wibtoft, UK). Optical spectra were obtained from the prepared solution by measuring the absorption of the solution in a quartz cuvette with a $1 \mathrm{~cm}$ optical path. The optical properties were monitored for a period of 6 days to test the solution stability. Ultrastructural observations were performed by a Hitachi 7700 TEM, operating at $100 \mathrm{kV}$ (Hitachi High Technologies America Inc., Dallas, TX, USA). For TEM observations specimens were placed as small droplets of NPs solutions onto standard carbon supported 600-mesh copper grids and let to slowly air dry. To determine the NPs distribution sizes, 50 fields
$(150 \times 100 \mathrm{~nm})$ were randomly chosen and analyzed by using the image software Image J (US NIH, Bethesda, MD, USA).

\subsection{Biocompatibility Test}

Human epithelioid cervix carcinoma cells (HeLa) were routinely cultured in EMEM (Cambrex, Verviers, Belgium) supplemented with $10 \%$ fetal calf serum, $2 \mathrm{mM}$ L-glutamine (Cambrex, Verviers, Belgium), $100 \mathrm{IU} / \mathrm{ml}$ penicillin and streptomycin solution and $10000 \mathrm{U} / \mathrm{ml}$ nystatin (antimicotic solution) (Cambrex, Verviers, Belgium), in a $5 \% \mathrm{CO}_{2}$ humidified atmosphere at $37^{\circ} \mathrm{C}$.

For all experiments, HeLa cells were harvested from subconfluent cultures by trypsinization, resuspended in fresh complete medium and plated into 6-well plates at a density of $1.5 \times 10^{5}$ cells $/ \mathrm{mL}$. 
After $24 \mathrm{~h}$ incubation, the culture medium was replaced with a fresh one containing variable concentrations of C-NPs $\left(8 \times 10^{5}, 1.6 \times 10^{6}, 3.2 \times 10^{6}, 8 \times 10^{6}, 1.6 \times 10^{7} \mathrm{C}-\mathrm{NPs} /\right.$ cell $)$. Cells viability was assayed after 4,24 and $48 \mathrm{~h}$ of incubation with C-NPs. In each experiment, untreated cells served as negative control. At least six independent experiments and two replicates for each C-NPs concentration were done. At fixed times after C-NPs exposure, the culture medium was discharged, the cells were washed two times with PhosphateBuffered Saline (PBS) and fresh culture medium containing 1 $\mathrm{mg} / \mathrm{mL} \quad$ of 3-(4,5-dimethylthiazol-2-yl)-2,5diphenyltetrazolium bromide salt (MTT) was added to each well. After $2 \mathrm{~h}$ incubation at $37^{\circ} \mathrm{C}$ in a $5 \% \mathrm{CO}_{2}$ humidified atmosphere, the MTT, reduced by the mitochondrial reductase of vital cells, produced a dark insoluble product, formazan salt. Then, the formazan salts were dissolved in DiMethylSulfOxide (DMSO), leading to a violet solution whose absorbance was measured with Ultrospec 4000 UVvisible spectrophotometer (Pharmacia Biotech, Stockholm, Sweden) at $570 \mathrm{~nm}$. Viability was expressed in percentage as the Relative Growth Rate (RGR) by the equation:

$$
\mathrm{RGR}=\left(\mathrm{D}_{\text {sample }} / \mathrm{D}_{\text {control }}\right) \times 100
$$

where $D_{\text {sample }}$ and $D_{\text {control }}$ are respectively the absorbance of the test samples and the negative controls.

\subsection{Statistical Analysis}

Data were analyzed by performing one-way ANalysis Of VAriance (ANOVA) at the 95\% confidence level. P values less than 0.05 were considered significant.

\section{Results}

\subsection{C-NPs Characterization}

A basic step in the study of NPs cytotoxicity is the detailed description of their characteristics that are strictly dependent on synthesis procedures. The shape, size and stability of the C-NPs used in this work were carefully characterized using TEM and spectroscopy. TEM images (Fig. 1) of C-NPs show that NPs have spherical shape and are polydisperse in the solution. Morphometry of the TEM images provides C-NPs size and size distribution, that ranges from 4 to $10 \mathrm{~nm}$ with an average diameter of $7 \mathrm{~nm}$ as reported in Table 2. The time of the electrochemical synthesis (i.e., 90, 150 and $190 \mathrm{~min}$ ) as well as the sterility protocols did not affect NPs size, size distribution and dispersion (Table 2).

UV-visible spectra are recorded soon after synthesis and after 6 days in complete EMEM culture medium in the range between 200 and $1000 \mathrm{~nm}$. In Fig. 1 we report the data about stability of C-NPs solutions obtained applying $90 \mathrm{~min}$ of synthesis. In fact, the time of the electrochemical process does not influence the stability of the C-NPs solutions. The peak at $236 \mathrm{~nm}$ indicates the presence of C-NMs in the solution (Figs 1a,c,d). The treatment at $121^{\circ} \mathrm{C}$ and $2 \mathrm{~atm}$ for 20 min affects the spectroscopic absorbance of C-NPs as showed by the shift of the peak from $236 \mathrm{~nm}$ to $257 \mathrm{~nm}$ (Fig. 1b). The well-defined peaks at $236 \mathrm{~nm}$ or at $257 \mathrm{~nm}$ show stability of C-NPs over time without aggregation and sedimentation.

Table 2. Size distribution of freshly synthesized C-NPs.

\begin{tabular}{lll}
\hline $\begin{array}{l}\text { Application } \\
\text { time of } \\
\Delta \mathbf{V ~ ( 3 0 ~ V )}\end{array}$ & $\begin{array}{l}\text { Sterile protocols (before } \\
\text { and/or after C-NPs } \\
\text { administration to cells) }\end{array}$ & $\begin{array}{l}\text { Average diameter } \pm \\
\text { SD }^{*}(\mathbf{n m})\end{array}$ \\
\hline \multirow{2}{*}{$\mathbf{0} \mathrm{min}$} & None & $7 \pm 3$ \\
& Autoclaved twice & $7 \pm 2$ \\
$150 \mathrm{~min}$ & $\begin{array}{l}\text { Synthesis under sterile } \\
\text { conditions }\end{array}$ & $7 \pm 2$ \\
$190 \mathrm{~min}$ & Microfiltration & $6 \pm 2$ \\
\hline
\end{tabular}

* To determine the C-NPs distribution sizes 50 randomly fields of $150 \times 100$ $\mathrm{nm}$ were analysed by using the image software Image J (US NIH, Bethesda, $\mathrm{MD}, \mathrm{USA}) ; \Delta \mathrm{V}=$ electric potential difference.

\subsection{Biocompatibility of C-NPs}

To investigate whether the different parameters, i.e., time of synthesis and sterilization procedures, used for obtaining C-NPs solution can interfere with biocompatibility and/or toxicity, HeLa cells were exposed to increasing C-NPs concentrations $\left(8 \times 10^{5}, 1.6 \times 10^{6}, 3.2 \times 10^{6}, 8 \times 10^{6}, 1.6 \times 10^{7}\right.$ $\mathrm{NPs} /$ cell) for different times (4, 24 and $48 \mathrm{~h})$. As expected, our results indicate that cell viability is C-NPs concentrationand time of culture-dependent. Interestingly, for the first time is here reported that also the time of electrolysis process used during particles synthesis and procedures adopted to sterilize C-NPs solutions largely influenced cells response. In Fig. 2 we report representative data about cell viability of C-NPs solutions. In general, the highest toxicity was always measured at 24 and $48 \mathrm{~h}$, irrespective of the modality of synthesis of C-NPs and concentration used. Conversely, at the shortest time of incubation examined, $3.2 \times 10^{6} \mathrm{NPs} /$ cell prepared during $90 \mathrm{~min}$ of electrolysis was the most toxic NPs preparation, inducing more than $20 \%$ of viability reduction. The greater reduction in cell viability (ranging between 30 and $50 \%$ ) was observed in the presence of the highest C-NPs concentrations $\left(8 \times 10^{6}\right.$ and $1.6 \times 10^{7} \mathrm{NPs} /$ cell $)$ at 24 and $48 \mathrm{~h}$ of culture (Fig. $2 \mathrm{a}$ ). In the presence of C-NPs prepared during $90 \mathrm{~min}$ of electrolysis process, a generalized cell viability reduction was found after $4 \mathrm{~h}$ of culture; differences were related to NPs concentrations. Conversely, C-NPs prepared during $90 \mathrm{~min}$ of electrolytic process and autoclaved for two cycles at $121^{\circ} \mathrm{C}$ and 2 atm for $20 \mathrm{~min}$ were not toxic for HeLa cells even at $48 \mathrm{~h}$ of treatment (Fig. 2b). Noteworthy, they induced a significant cell viability increase (120\% vs 100\% of the untreated cells) (Fig. 2b). By increasing the electrolytic synthesis times, i.e., 150 and 190 min, C-NPs treatment caused a significant inhibition of cell growth, reaching values of around $40 \%$ survival in the presence of the $1.6 \times 10^{7} \mathrm{NPs} /$ cell (Figs 2c,d). Shorter treatments, i.e., $4 \mathrm{~h}$ with $\mathrm{C}-\mathrm{NPs}$, were not toxic independently on C-NPs concentrations; in addition, $8 \times 10^{6}$ and $1.6 \times 10^{7} \mathrm{C}$ NPs/cell induced HeLa cells proliferation respectively of $130 \%$ and $140 \%$ (Figs. 2c,d). A similar trend was observed when CNPs were obtained at the longest electrolytic synthesis time, i.e., $190 \mathrm{~min}$; indeed, the peak of proliferation was significant 
higher (Fig. 2d).

The major morphological changes of HeLa cells treated with C-NPs, monitored at inverted Light Microscope (LM),

a)
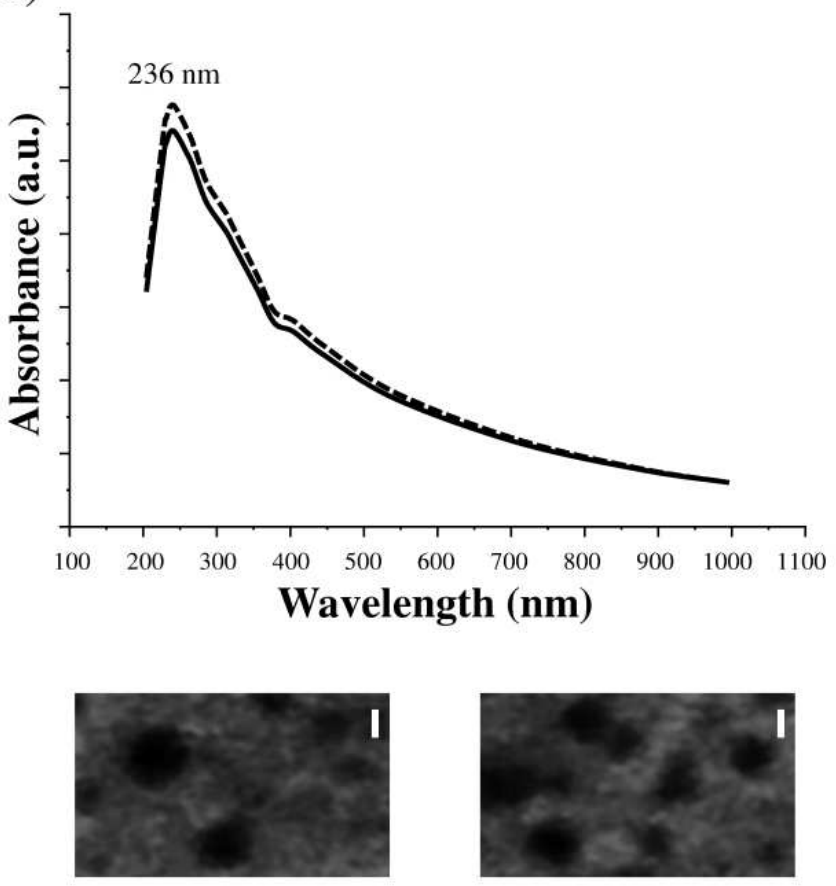

- C-NPs freshly synthetized

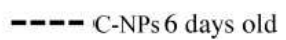

c)
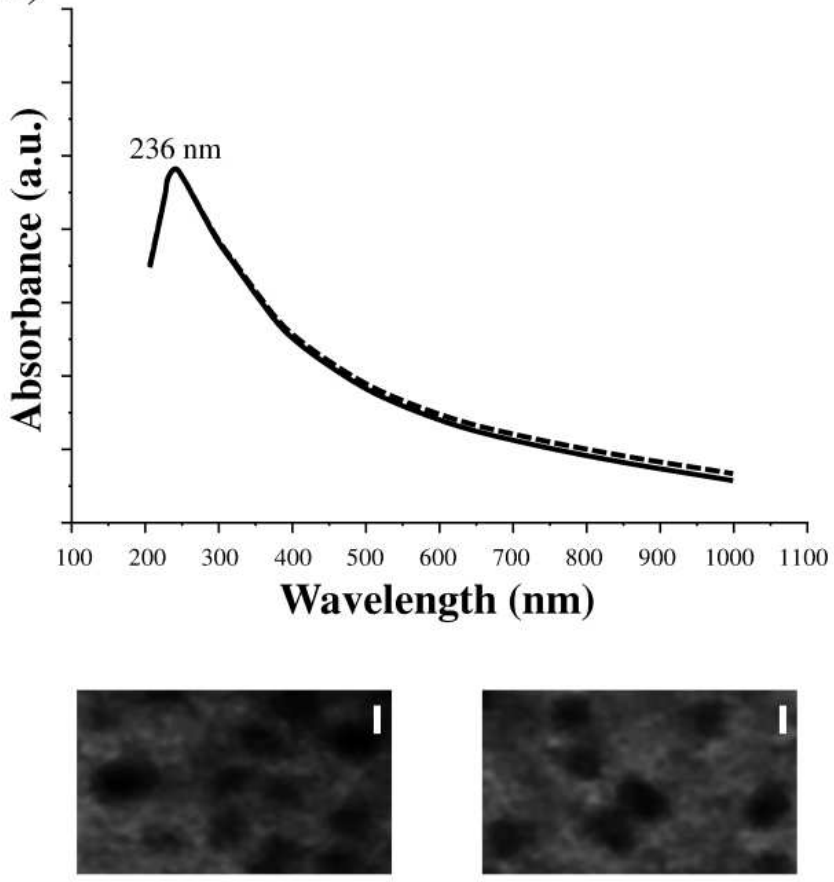

C-NPs freshly synthetized are elongation of the cellular body and substrate detachment (Fig. 2).

b)
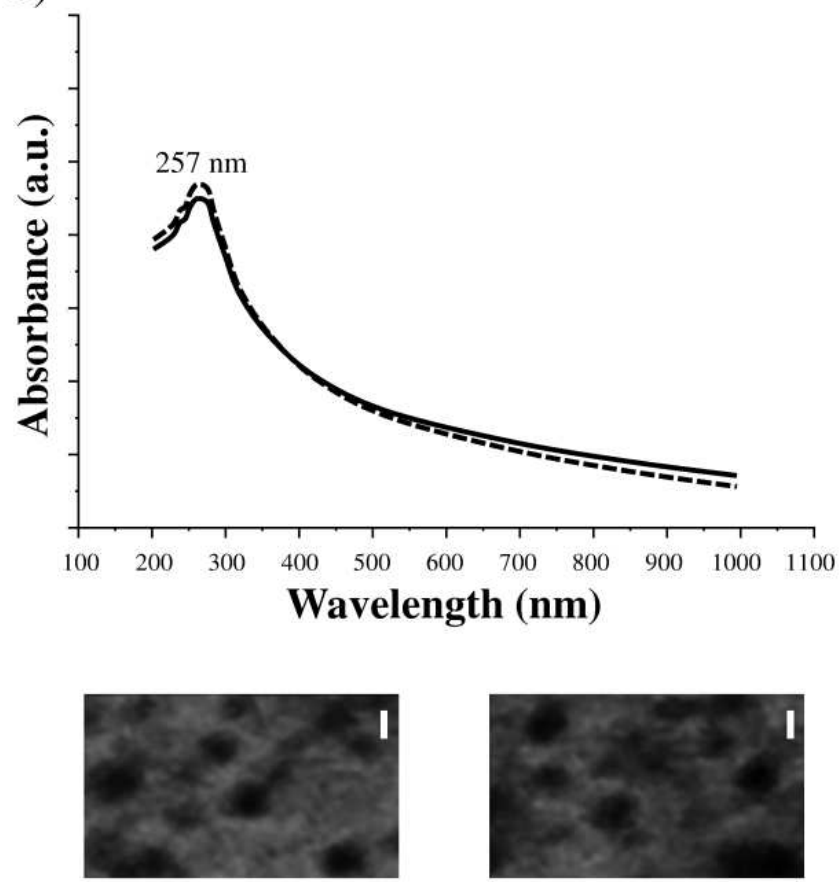

- C-NPs freshly synthetized

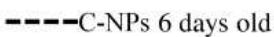

d)
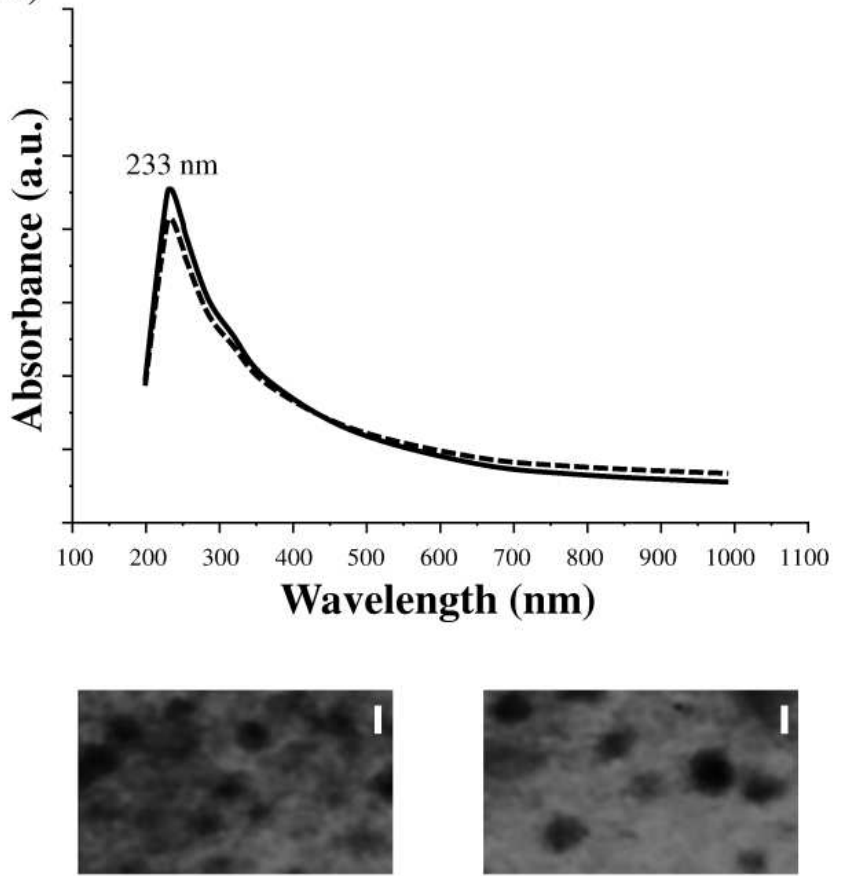

C-NPs freshly synthetized

Figure 1. Spectroscopy and TEM of C-NPs freshly prepared and 6 days old in EMEM after different sterilization procedures. UV-visible absorbance spectra and TEM pictures are referring to C-NPS synthesized via electrochemical process at $30 \mathrm{~V}$ electric potential difference for 90 min in different condition of sterility: C-NPs (a) synthesized without sterility, (b) autoclaved twice, (c) synthesized under sterile conditions or (d) microfiltered. Each curve represents the mean of six independent experiments, each done in duplicate. The SDs are under the limit to be plotted. TEM micrographs of C-NPs synthesized at $30 \mathrm{~V}$ for 90 min with different sterilization protocols as above reported; bar $=5 \mathrm{~nm}$ 
a)
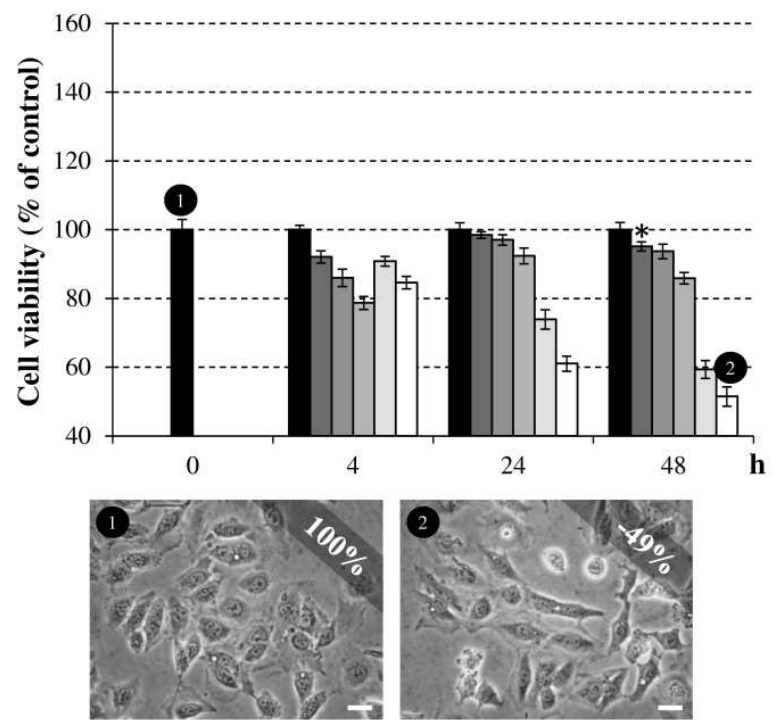

b)

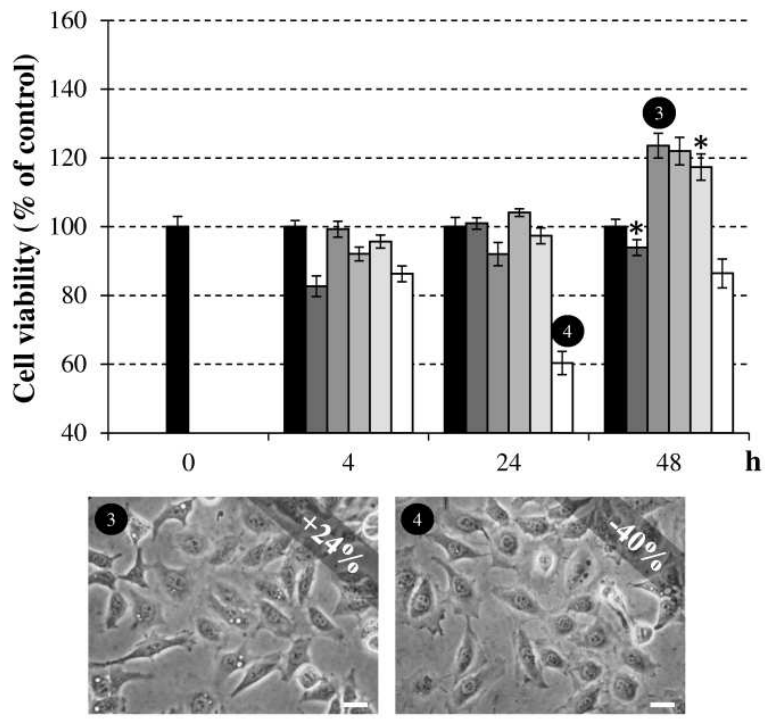

Ctrl $\square 8 \times 10^{5} \mathrm{C}-\mathrm{NPs} / \mathrm{cell} \quad \square 1.6 \times 10^{6} \mathrm{C}-\mathrm{NPs} / \mathrm{cell}$

c)

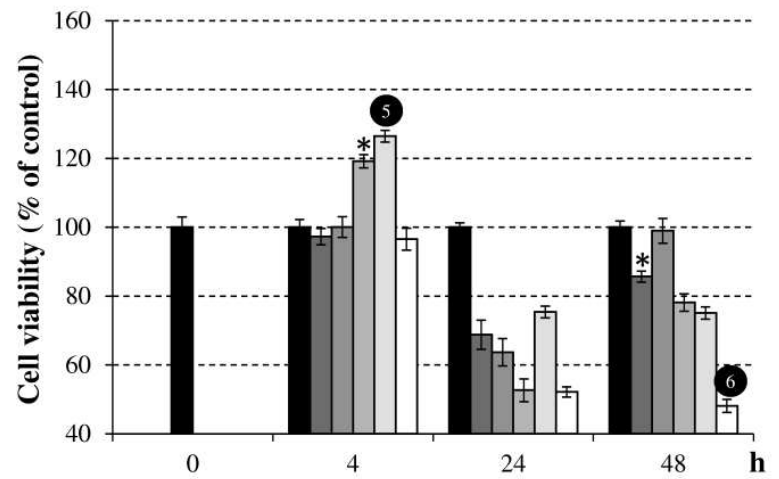

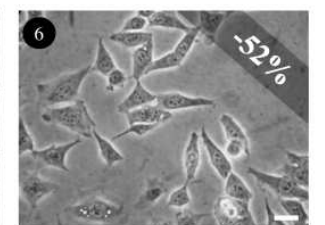

$3.2 \times 10^{6} \mathrm{C}-\mathrm{NPs} / \mathrm{cell}$

$8 \times 10^{6} \mathrm{C}-\mathrm{NPs} / \mathrm{cell}$

$1.6 \times 10^{7} \mathrm{C}-\mathrm{NPs} / \mathrm{cell}$

d)

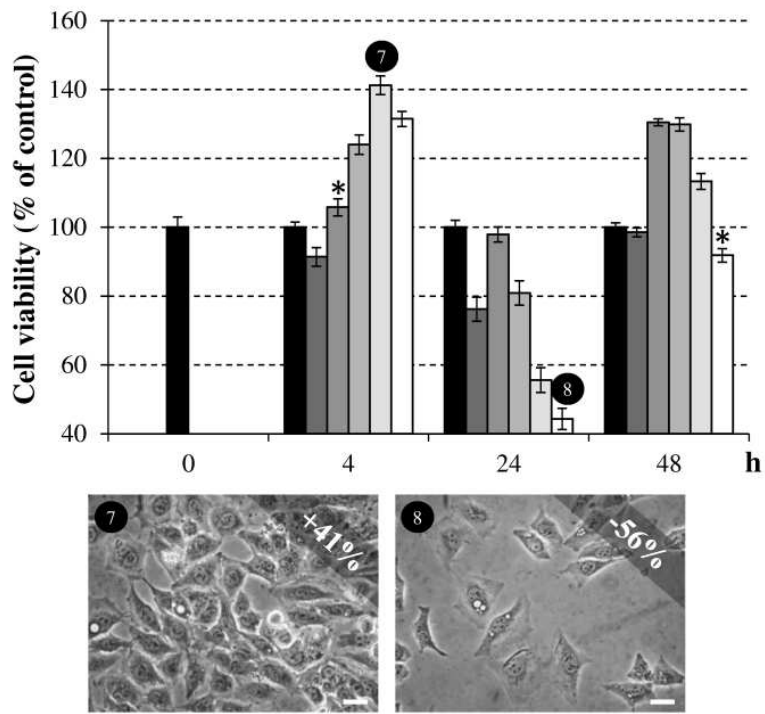

Figure 2. Cell viability of HeLa cells up to $48 \mathrm{~h}$ of incubation with different amounts of C-NPs synthesized at $30 \mathrm{~V}$ for different times with or without different sterilization protocols. HeLa cells viability was assayed in the presence of different amounts of C-NPs by MTT assay: C-NPs (a) synthesized for 90 min in non sterile condition, (b) autoclaved twice after 90 min of synthesis, (c) synthesized for 150 min under sterile conditions or (d) synthesized for 190 min and microfiltered. The values are reported as percentage of the control untreated cells considered as $100 \%$. Each value represents the mean $\pm S D$ of six independent experiments, each done in duplicate. Star indicates significant value with respect to the corresponding control value at the same time point $(p<0.05)$. Ctrl (control) $=$ untreated cells; $h=$ hours. LM micrographs show HeLa cells in culture and the treatment refers to the histogram above. The number on the picture refers to the column with the corresponding number. The changes of cell viability are indicated as increased (+) or decreased (-) percentages with respect to the control untreated cells taken as 100\%; bar $=10 \mu \mathrm{m}$.

\section{Discussion}

In this work, we used an electrolysis process to obtain CNPs from graphite. In particular, we evaluated different times and sterile conditions during and/or after electrochemical synthesis on features of C-NPs, in terms of size, shape and stability. Moreover, we evaluated the biocompatibility of the different C-NPs solutions in HeLa cells by using different
NPs amounts and different times of incubation.

Here we demonstrated that synthesis and sterilization protocols have no effect on the average diameter $(7 \mathrm{~nm})$ and shape (spherical) of the C-NPs neither on the stability over 6 days of storage. Indeed, NPs show typical peak of absorbance at $236 \mathrm{~nm}$ and do not aggregate and sediment. Conversely, high temperature $\left(121^{\circ} \mathrm{C}\right)$ and pressure $(2 \mathrm{~atm})$ caused a shift of the peak at $257 \mathrm{~nm}$, suggesting putative 
chemical features change as demonstrated by preliminary Raman characterizations (data not shown), without affecting the stability over time.

$\mathrm{C}-\mathrm{NMs}$ are the most exploited in biomedical engineering as cell and tissue labeling and imaging [31], drug delivery systems [32] and reinforcing tissue engineering scaffold [33]. Despite many successful applications in biomedical engineering, there is a growing concern for safety with $\mathrm{C}$ NPs and biocompatibility, which are essential requisites for biomedical applications. Conflicting reports exist regarding the toxicity of C-NMs, that largely stem from the variability of material properties (i.e., size and surface) and model used (i.e., in vivo vs in vitro, cell types, tissues considered and animals types) [34]. In vitro studies suggest that cytotoxicity of C-NMs depends on their cellular uptake, agglomeration and induced oxidative stress; conversely, most studies in vivo have shown that C-NMs do not cause significant toxicity [3536]. Our previous studies have demonstrated the toxicity induced of C-NPs on P. lividus development [28-30]. In particular, C-NPs interfere with biomineralization process during skeletogenesis. In addition C-NPs ingested by $P$. lividus sea urchin pluteus induce a defense response by the animals [30].

The results here reported suggest that the time of synthesis is pivotal in cellular response. The toxicity of the C-NPs solution obtained at 90 min of synthesis process without any sterilization procedure is the more toxic, probably due to the presence of contaminants in the solution. On the other hand, by sterilizing the solution, the viability of HeLa cells significantly increased. In particular, the change in chemical characteristics of C-NPs observed in solution sterilized by twice autoclaving positively influence the interaction with HeLa cells, as suggested by the absence of cell toxicity. Conversely, the C-NPs synthesized during $150 \mathrm{~min}$ of electrolysis process and microfiltered after synthesis affect cell viability in a concentration and time dependent manner.

\section{Conclusion}

In conclusion, our results suggest that the synthesis procedure is crucial in inducing cellular response in terms of cytotoxicity. In fact, synthesis affects size, morphology, stability and properties (chemical and physical) of the NMs. Thus, very important is the effort of researchers to develop procedures for producing reproducible, stable and biocompatible NMs. Also, more systematic biological evaluations of C-NMs induced effects are important in order to determine their precise pharmacokinetics, cytotoxicity and optimal dosages. In fact, deeper investigation, such as uptake by the cells, intracellular localization, and cellular metabolism, are need to be better evaluated in relation to synthesis and sterilization protocols of C-NPs biocompatible.

These concerns highlight the pivotal role that nanometrological techniques play in different scientific and industrial fields, since they allow to yield information of surface features, shape, size and structure of NMs as well as of their intracellular uptake and localization.

\section{Acknowledgement}

The authors gratefully acknowledge Prof. D. Manno (University of Salento, Lecce, Italy) for providing C-NPs.

\section{References}

[1] A. Krueger, Carbon materials and nanotechnology. WileyVCH, Weinheim, 2010.

[2] C. Berger, Z. M. Song, X. B. Li, X. S. Wu, N. Brown, C. Naud,D. Mayo, T. B. Li, J. Hass, A. N. Marchenkov, E. H. Conrad, P. N. First, and W. A. de Heer, "Electronic confinement and coherence in patterned epitaxial graphene," Science, vol. 312, pp. 1191-1196, 2006.

[3] S. Gilje, H. Song, M. Wang, K. L. Wang, and R. B. Kaner, "A chemical route to graphene for device applications," Nano Lett., vol. 7, pp. 3394-3398, 2007.

[4] Y. G. Guo, Y. S. Hu, and J. Maier, "Synthesis of hierarchically mesoporous anatase spheres and their application in lithium batteries," Chem. Commun., vol. 26, pp. 2783-2785, 2006.

[5] Z. Y. Yuan and B. L. Su, "Insights into hierarchically mesomacroporous structured materials," J. Mater. Chem., vol. 16, pp. 663-677, 2006.

[6] L. Quercia, F. Loffredo, B. Alfano, V. La Ferrara, and G. Di Francia, "Fabrication and characterization of carbon nanoparticles for polymer based vapor sensors," Sens. Actuators, B, vol. 100, pp. 22-28, 2004.

[7] Y. Li, X. Fan, J. Qi, J. Ji, S. Wang, G. Zhang, and F. Zhang, "Palladium nanoparticle-graphene hybrids as active catalysts for the Suzuki reaction," Nano Res., vol. 3, pp. 429-437, 2010.

[8] J. Lee, S. Yoon, T. Hyeon, S. M. Oh, and K. B. Kim, "Synthesis of a new mesoporous carbon and its application to electrochemical double-layer capacitors," Chem. Commun., vol. 21, pp. 2177-2178, 1999.

[9] H. Yang, Q. Shi, X. Liu, S. Xie, D. Jiang, F. Zhang, C. Yu, B. $\mathrm{Tu}$, and D. Zhao, "Synthesis of ordered mesoporous carbon monoliths with bicontinuous cubic pore structure of Ia3d symmetry," Chem. Commun., vol. 23, pp. 2842-2843, 2002.

[10] M. D. Stoller, S. Park, Y. Zhu, J. An, and R. S. Ruoff, "Graphene-based ultracapacitors," Nano Lett., vol. 8, pp. 3498-3502, 2008.

[11] B. S. Harrison and A. Atala, "Carbon nanotube applications for tissue engineering," Biomaterials, vol. 28, pp. 344-353, 2007.

[12] L. Cao, X. Wang, M. J. Meziani, F. Lu, H. Wang, P. G. Luo, Y. Lin, B. A. Harruff, L. M. Veca, D. Murray, S. Y. Xie, and Y. P. Sun, "Carbon dots for multiphoton bioimaging," J. Am. Chem. Soc., vol. 129, pp. 11318-11319, 2007.

[13] Y. P. Sun, B. Zhou, Y. Lin, W. Wang, K. A. Fernando, S. P. Pathak,M. J. Meziani, B. A. Harruff, X. Wang, H. Wang, P. G. Luo,H. Yang, M. E. Kose, B. Chen, L. M. Veca, and S. Y. Xie, "Quantum-sized carbon dots for bright and colorful photoluminescence," J. Am. Chem. Soc., vol. 128, pp. 77567757,2006

[14] T. W. Kim, P. W. Chung, I. I. Slowing, M. Tsunoda, E. S. Yeung, and V. S. Y. Lin, "Structurally ordered mesoporous carbon nanoparticles as transmembrane delivery vehicle in human cancer cells," Nano Lett., vol. 8, pp. 3724-3727, 2008. 
[15] Z. Liu, J. T. Robinson, X. Sun, and H. Dai, "PEGylated nanographene oxide for delivery of water-insoluble cancer drugs," J. Am. Chem. Soc., vol. 130, pp. 10876-10877, 2008.

[16] H. Liu, T. Ye, and C. Mao, "Fluorescent carbon nanoparticles derived from candle soot," Angew. Chem., Int. Ed., vol. 46, pp 6473- 6475, 2007.

[17] A. Galvez, N. Herlin-Boimeb, C. Reynaudb, C. Clinarda, and J. N. Rouzaud, "Carbon nanoparticles from laser pyrolysis," Carbon, vol. 40, pp. 2775-2789, 2002.

[18] Y. Yan, H. Yang, F. Zhang, B. Tu, and D. Zhao, "Lowtemperature solution synthesis of carbon nanoparticles, onions and nanopores by the assembly of aromatic molecules," Carbon, vol. 45, pp. 2209-2216, 2007.

[19] Q. L. Zhao, Z. L. Zhang, B. H. Huang, J. Peng, M. Zhang, and D. W. Pang, "Facile preparation of low cytotoxicity fluorescent carbon nanocrystals by electrooxidation of graphite," Chem. Commun., vol. 41, pp. 5116-5118, 2008.

[20] H. Zhu, X. Wang, Y. Li, Z. Wang, F. Yang, and X. Yang, "Microwave synthesis of fluorescent carbon nanoparticles with electrochemiluminescence properties," Chem. Commun., vol. 34, pp. 5118-5120, 2009.

[21] S. J. Yu, M. W. Kang, H. C. Chang, K. M. Chen, and Y. C. Yu, "Bright fluorescent nanodiamonds: no photobleaching and low cytotoxicity," J. Am. Chem. Soc., vol. 127, pp. 17604-17605, 2005.

[22] R. Selvi, D. Jagadeesan, B. S. Suma, G. Nagashankar, M. Arif, K. Balasubramanyam, M. Eswaramoorthy, and T. K. Kundu, "Intrinsically fluorescent carbon nanospheres as a nuclear targeting vector: delivery of membrane-impermeable molecule to modulate gene expression in vivo," Nano Lett., vol. 8, pp. 3182-3188, 2008

[23] V. N. Mochalin and Y. Gogotsi, "Wet chemistry route to hydrophobic blue fluorescent nanodiamond," J. Am. Chem. Soc., vol. 131, pp. 4594-4595, 2009.

[24] Z. Wang, F. Li, and A. Stein, "Direct synthesis of shaped carbon nanoparticles with ordered cubic mesostructure," Nano Lett., vol. 7, pp. 3223-3226, 2007.

[25] Tang, K. Qi, K. L. Wooley, K. Matyjaszewski, and T. Kowalewski, "Well-Defined Carbon Nanoparticles Prepared from Water-Soluble Shell Cross-linked Micelles that Contain Polyacrylonitrile Cores," Angewandte Chemie, vol. 116, pp. 2843-2847, 2004.
[26] L. Dini, E. Panzarini, S. Mariano, D. Passeri, M. Reggente, M. Rossi, and C. Vergallo, "Microscopies at the nanoscale for nano-scale drug delivery systems," Curr. Drug Targets, 2015, in press.

[27] K. Donaldson, L. Tran, L. A. Jimenez, R. Duffin, D. E. Newby, N. Mills, W. MacNee, and V. Stone, "Combustion-derived nanoparticles: a review of their toxicology following inhalation exposure," Part. Fibre Toxicol., vol. 2, p. 10, 2005.

[28] D. Manno, E. Carata, B.A. Tenuzzo, E. Panzarini, A. Buccolieri, E. Filippo, M. Rossi, A. Serra, and L. Dini, "High ordered biomineralization induced by carbon nanoparticles in the sea urchin Paracentrotus lividus," Nanotechnology, vol. 23, p. 495104, 2012.

[29] E. Carata, B. Anna Tenuzzo, F. Arnò, A. Buccolieri, A. Serra, D. Manno, and L. Dini, "Stress response induced by carbon nanoparticles in Paracentrotus lividus," Int. J. Mol. Cell. Med., vol. 1, pp. 30-38, 2012.

[30] D. Manno, A. Serra, A. Buccolieri, E. Panzarini, E. Carata, B. Tenuzzo, D. Izzo, C. Vergallo, M. Rossi, and L. Dini, "Silver and carbon nanoparticles toxicity in sea urchin Paracentrotus lividus embryos," BioNanoMat., vol. 14, pp. 229-238, 2013.

[31] A. Bianco, K. Kostarelos, C. D. Partidos, and M. Prato, "Biomedical applications of functionalised carbon nanotubes," Chem Commun (Camb) vol. 5, pp. 571-577, 2005.

[32] S. R. Shin, H. Bae, J. M. Cha, J.Y. Mun, Y.C. Chen, H. Tekin, H. Shin, S. Farshchi, M. R. Dokmeci, S. Tang, and A. Khademhosseini, "Carbon nanotube reinforced hybrid microgels as scaffold materials for cell encapsulation," ACS Nano., vol. 6, pp. 362-372, 2012.

[33] C. Cha, S.R. Shin, N. Annabi, M.R. Dokmeci, and A. Khademhosseini, "Carbon-based nanomaterials: multifunctional materials for biomedical engineering," ACS Nano, vol. 7, pp. 2891-2897, 2013.

[34] S.T. Yang, J. Luo, Q. Zhou, and H. Wang, "Pharmacokinetics, metabolism and toxicity of carbon nanotubes for biomedical purposes," Theranostics, vol. 2, pp. 271-282, 2012.

[35] C.W. Lam, J.T. James, R. Mc Cluskey, S. Arepalli, and R.L. Hunter, "A review of carbon nanotube toxicity and assessment of potential occupational and environmental health risks," Crit. Rev. Toxicol., vol. 36, pp. 189-217, 2006.

[36] C.P. Firme and P.R. Bandaru, "Toxicity issues in the application of carbon nanotubes to biological systems," Nanomedicine, vol. 6, pp. 245-56, 2010. 